NASA Contractor Report 189129

\title{
Rotary Engine Performance Limits Predicted by a Zero-Dimensional Model
}

Timothy A. Bartrand and Edward A. Willis

Sverdrup Technology, Inc.

Lewis Research Center Group

Brook Park, Ohio

March 1992

Prepared for

Lewis Research Center

Under Contract NAS3-25945

\section{N/SA \\ National Aeronautics and \\ Space Administration}

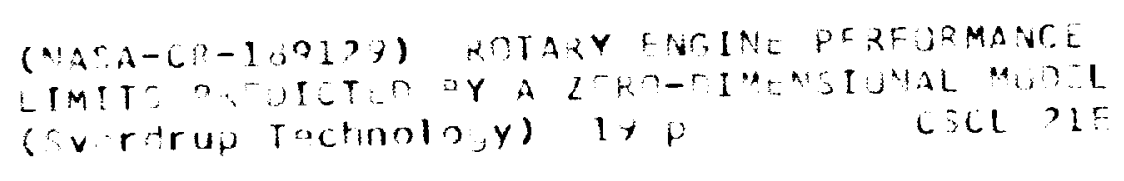

$N 2=-20050$ 


\title{
Rotary Engine Performance Limits Predicted by a Zero-Dimensional Model
}

\author{
Timothy A. Bartrand and Edward A. Willis \\ Sverdrup Technology, Inc. \\ Lewis Research Center Group \\ Brook Park, Ohio 44142
}

\begin{abstract}
A parametric study was performed to determine the performance limits of a rotary combustion engine. This study shows how well increasing the combustion rate, insulating and turbocharging increase brake power and decrease fuel consumption. Several generalizations can be made from the findings. First, it was shown that the fastest combustion rate is not necessarily the best combustion rate. Second, several engine insulation schemes were employed for a turbocharged engine. Performance improved only for a highly insulated engine. Finally, the viability of turbocompounding and the influence of exhaust port shape were calculated.
\end{abstract}

Rotary engine performance was predicted by an improved zero-dimensional computer model based on a model developed at the Massachusetts Institute of Technology in the 1980s. Independent variables in the study included combustion heat release rate, manifold pressures, wall thermal properties, leakage area and exhaust port geometry. Additions to the computer program since its results were last published include turbocharging, manifold modeling and improved friction power loss calculation. The baseline engine for this study is a single rotor $650 \mathrm{cc}$ direct-injection stratified-charge engine with aluminum housings and a stainless steel rotor. Engine maps are provided for the baseline and turbocharged versions of the engine.

\section{INTRODUCTION}

This paper contains details of a parametric study on the influence of combustion, charging, geometry and heat transfer on the performance of a turbocharged, direct-injection stratified-charge (DISC) rotary combustion engine ( $\mathrm{RCE}$ ). A computer program calculated engine performance for a baseline engine and numerous perturbations from the baseline engine. The program's heart is a zero dimensional thermodynamic cycle model. From the resulting performance data, insights were gained into DISC RCE performance. Promising avenues for performance improvement were identified.

Froede ran the first practical RCE around 35 years ago [1].* Consequently, rotary engine development is less mature than crank-piston engine development. However, recent years have seen rapid improvements in engine brake specific fuel consumption ( $b s f c$ ), output power and reliability. By 1989, it was possible to run a two rotor, $1.72 \mathrm{l}\left(105 \mathrm{in}^{3}\right)$ DISC RCE at $320 \mathrm{~kW}(430 \mathrm{hp})$ and $b s f c$ around 255 $\mathrm{g} / \mathrm{kW}-\mathrm{h}(0.42 \mathrm{lb} / \mathrm{hp}-\mathrm{h})$ [2]. The same engine has a projected time before overhaul (TBO) of $2000 \mathrm{hr}$. In another dramatic demonstration of rotary engine durability, a Mazda 4-rotor engine powered the winning car in this year's Lemans 24-hour endurance race [3]. Part of the Mazda entry's success was attributed to a new apex seal design. These anecdotes indicate that the rotary engine's traditional downfalls of poor fuel economy, sealing and reliability are being addressed, making the DISC RCE a strong competitor with four-stroke crank-piston SI and CI engines.

As engineers continue to improve the RCE, the 0-D thermodynamic cycle model and other computer programs are useful in adding direction to their efforts. Since the 0 -D model is less complex than multi-dimensional models, it incorporates en-

* Numbers in square brackets indicate references. 
gine features not included in those models (e.g., friction, leakage, turbocharging and ancillary losses) and is less expensive to run. The $0-D$ model is flexible enough to incorporate hypothetical engine conditions such as extremely fast combustion, very high chamber pressures or very well insulated walls. In this paper, three avenues for performance improvement were examined using the $0-\mathrm{D}$ model: faster combustion; enhanced turbocharging and low-heatrejection (LHR) component coatings. Some of the engine configurations used were realistic; others are hypothetical. The remainder of the introduction describes the motivation and method for studying the three avenues of performance improvement.

In the past several years, considerable DISC RCE fuel consumption reductions have been realized. These are attributed primarily to changes in fuel injection proposed by Abraham [4],[5]. Current DISC RCEs employ two injectors: a pilot injector and a main injector. To study enhanced combustion, Abraham predicted engine performance with various fuel injection schemes. He discovered nonshadowing sprays (in which liquid streams are not "upwind" of other liquid streams) enhance mixing and lead to more rapid combustion. Consequently, current designs employ a dual stream pilot injector and a fan-spray main injector. Predicted performance gains were realized in engine tests.

As Abraham and Raju [6] continue to model engine designs for faster combustion, the following question should be answered: Does speeding up the combustion always improve performance? Addressing this question is a goal of this paper. Even without a full understanding of the combustion process, it is possible to impose hypothetical burning rates on the $0-D$ model and observe which burning rate profiles lead to best performance and whether there is a point of diminishing returns.

It has been suggested that LHR coatings might improve brake specific fuel consumption (Badgley et al. [7]). Three possibilities were given for why LHR coatings might improve performance. First, it was possible energy "saved" from flowing to the coolant would result in increased shaft work. Second, it was hoped higher wall temperatures would speedup burning or burn parcels of fuel near the wall that wouldn't normally burn. Finally, the "saved" energy, if it appeared in the exhaust stream, would lead to more turbocharger turbine work and greater boost. A thin LHR coating was applied to the rotor of a DISC RCE and performance with and without the coating was compared [8]. There was no significant difference in performance when the coated rotor was used. That there was no improvement was explained by Bartrand and Willis [9]. First, the fraction of fuel energy lost to cooling the rotor was only about $4.5 \%$ of the fuel energy introduced each cycle. To make a large difference in performance, LHR coatings must block nearly all the energy loss to the rotor. Second, the thermal resistance offered by a thin LHR coating may not be sufficient to reduce heat rejection enough to change performance. The $0-D$ model used in reference 9 did not include turbocharging and did not account for any change in the combustion rate when LHR components were employed.

The use of LHR components is explored again in this paper. The same cases as in reference 9 are studied. However, this time, turbocharging is included. The configurations studied are: the baseline engine (aluminum housings and iron rotor); baseline engine with LHR trochoid housing coating; baseline engine with LHR rotor coating; baseline engine with all components coated with LHR coatings; all-titanium engine; engine with very well-insulated components and a no-heat-transfer engine.

Finally, like other DISC engines, turbocharging increases RCE brake power without fuel consumption or emissions penalties. In addition, because the rotary engine exhaust energy is more energetic than crank-piston engine exhaust energy [9], the RCE is suited particularly well to turbocharging. To take advantage of turbocharging fully, the turbocharger system and engine should match. Results from several turbocharging studies are included in this paper. First, a turbocharged engine map was produced for comparison with the baseline, naturally aspirated engine map. Next, to explore the viability of turbocompounding, the influence of back pressure on output, fuel consumption and air flow rate is shown. Finally, the influence of exhaust port position (timing) on turbocharged engine performance is shown. Exhaust port area and timing are very important at high engine loads and speeds and may limit maximum output.

\section{METHOD}

As described above, this paper presents three studies: the influence of combustion rate, turbocharging and component materials on rotary engine performance. To begin, a baseline engine is described and a performance map for the naturally aspirated version of the engine is presented. The baseline engine is the NASA/Deere $662.5 \mathrm{cc}\left(40.43 \mathrm{in}^{3}\right.$ ) DISC RCE. Its dimensions are provided in Table 1. Estimated inputs are denoted with an asterisk. 
Table 1: Baseline Engine Dimensions

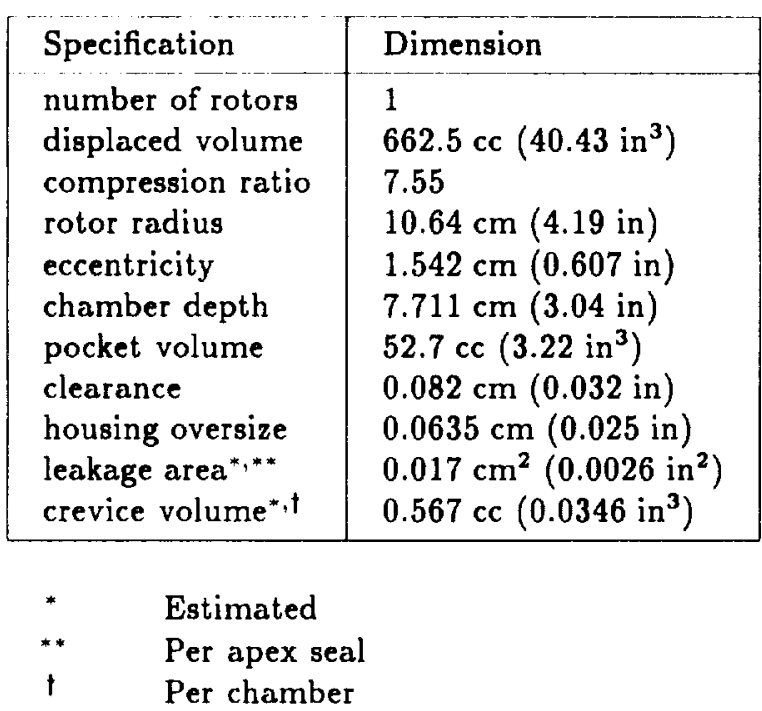

Engine performance was calculated by a $0-D$ thermodynamic cycle performance computer program. Older versions of the program are well documented ([9], [10], [11] and [12]). Since reference [9] was written, several additions were made to the program, including turbocharging/manifold modeling and improved friction and ancillary loss models. Turbocharger and manifold models were added in an effort to make the computer program compatible with the NASA/Navy Engineering Program (NNEP) aircraft engine mission analysis computer program. Intake and exhaust manifolds are well stirred, frictionless, insulated volumes. The intake manifold communicates with an aftercooler and the intake port. The exhaust manifold communicates with the exhaust port, a wastegate and the turbine. Compressor and turbine performance are taken from performance maps read by the program at its beginning.

The first results produced for this study describe the operation of the baseline naturally aspirated engine. The model was calibrated using engine pressure data. Model constants set in calibration were: fuel heat release rate parameters, incylinder heat transfer parameters, discharge coefficients, friction and ancillary loss parameters and leakage area and crevice volumes. These parameters are described below and their values are found in Table 2.

Fuel heat release occurs in two stages: a linear rise to a maximum heat release rate followed by an exponential fall in heat release rate, as shown in Figure 1. Heat release rate parameters include the combustion initiation crank angle, $\theta_{n}$, the angle at which heat release rate is a maximum, $\theta_{m}$, and the value of the maximum normalized heat release rate (equal to the actual heat release rate divided by the amount of fuel energy introduced per cycle), $\left(\begin{array}{c}d Q \\ d \theta\end{array}\right)_{m}^{*}$. The exponential decay constant, $\tau$, is dependent on the other three parameters. The linear-exponential heat release rate model was deduced after observation of heat release rate characteristics in direct-injection stratified-charge, singleinjector, single-spark-plug engines [i3]. The heat release rate parameters were calibrated by reproducing output power, peak pressure and brake specific fuel consumption ( $b s f c$ ) measured on an experimental NASA/John Deere and Co. turbocharged rotary engine at 4400 and $5500 \mathrm{rpm}$. In all studies except combustion studies, the same heat release rate parameters were used. Using the same heat release rate parameters is likely to lead to errors when conditions deviate significantly from calibrated conditions.

The simulation's RCE heat transfer model is based on the work of Woschni [14]. Stanten [15] applied Woschni's model to the DISC RCE. Briefly, Nusselt number is calculated via the relation

$$
N_{u}=\alpha R_{c}^{\beta}
$$

where $R_{c}$ is Reynolds number based on the chamber depth and average gas velocity. Average gas velocity is

$$
\begin{aligned}
& v_{g n s}=c_{1} v_{\text {rotor }}+ \\
& c_{2}\left(\begin{array}{c}
V \\
V_{i p c}
\end{array}\right)\left(\begin{array}{l}
T_{i p c} \\
P_{i p c}
\end{array}\right)\left(P-P_{n o n-f_{i r i n g}}\right)
\end{aligned}
$$

where $v$ is average gas velocity, $T$ is temperature, $P$ is pressure, $V$ is volume, $c_{1}$ and $c_{2}$ are constants, subscript ipc denotes a value at the time the intake port closes and subscript non - firing denotes gas pressure in a motored engine at the same crank angle. Constants $\alpha, \beta, c_{1}$ and $c_{2}$ are given in Table 2 . The first velocity component accounts for bulk gas velocity and the second for additional gas motion during combustion. Values for the constants were chosen based on previously-used values and because they matched predicted and measured cooling losses and wall temperatures.

Ancillary losses are given by the expression

$$
f m e p_{a}=f_{1}+f_{2}\left(\frac{N}{1000}\right)+f_{3}\left(\frac{N}{1000}\right)^{2}
$$


where $N$ is engine speed in rpm and $f_{1}, f_{2}$ and $f_{3}$ are calibration constants. The calibration constants were fixed by fitting equation 3 to motored engine friction data then subtracting the estimated friction losses associated with seals and bearings. Values for the constants are found in Table 2.

Table 2: Model Calibration Constants

\begin{tabular}{|c|l|}
\hline Constant & Value \\
\hline$\theta_{s}$ & $-30^{\circ}$ \\
$\theta_{m}$ & $+15^{\circ}$ \\
$\left(\begin{array}{c}d Q \\
d \theta\end{array}\right)_{m}^{*}$ & 0.025 \\
$\alpha$ & 0.037 \\
$\beta$ & 0.8 \\
$c_{1}$ & 0.5 \\
$c_{2}$ & 1.1 \\
$f_{1}$ & 0.3680 \\
$f_{2}$ & 0.1319 \\
$f_{3}$ & 0.0059 \\
\hline
\end{tabular}

Using the calibrated engine model, the authors generated performance data for a baseline, naturally aspirated DISC RCE operating between $4000 \mathrm{rpm}$ and $8000 \mathrm{rpm}$ and equivalence ratios from 0.35 to 0.75 . To quantify the influence of losses on the baseline engine, an engine map was then generated for an engine with no leakage or crevice flows. Finally, best performance was predicted for the engine with no leakage or crevice flows, no cooling losses and very fast combustion. Best engine results were compared to the air-standard Otto cycle.

After computing baseline engine performance, several parametric studies were performed. Features of the baseline engine were varied and their influence on engine performance was noted. First, the influence of combustion rate and timing was investigated. The three independent constants in the combustion model (combustion initiation time, timing for maximum heat release rate and the magnitude of the maximum heat release rate) were varied and results are presented.

Next, influence of insulating materials on turbocharged engine performance was predicted. This study is similar to the study performed by Bartrand and Willis [9] for a supercharged engine. However, the effects of enhanced exhaust gas energy on boost are now documented. Engine performance was predicted for engines made of various materials and compared to the baseline engine, a hypothetical highly-insulated engine, and a hypothetical no-heattransfer engine. The engines were run at $6500 \mathrm{rpm}$ and equivalence ratio equal to 0.65 . Output power, $b s f c$ and breakdown of where fuel energy is used are reported.

Finally, turbocharging was investigated. Turbomachine performance is read from user-supplied maps. Turbocharger speed is calculated at the end of each cycle and remains constant over the entire next cycle. Intake manifold pressure, exhaust manifold pressure, compressor pressure ratio and turbine pressure ratio are all allowed to vary during each cycle. Provisions exist for wastegating, but the engines studied for this paper were not wastegated. Using this turbocharger model, an engine map for a turbocharged engine was generated and compared to maps for the baseline naturally aspirated engine and the engine with no leakage or crevice flows.

After illustrating turbocharged engine performance, two studies were performed to explore enhanced turbocharging. First, back-pressure was varied while holding intake manifold pressure steady. Brake power and air flow rate are presented for several intake pressures and a range of back-pressures. From these data, the viability of adding a compounding turbine can be assessed. Second, exhaust port timing was altered and the changes in output and $b s f c$ were noted.

\section{RESULTS}

BASELINE ENGINE The first results describe the baseline engine and compare it with several idealized engines. Figure 1 is the engine map generated for the baseline naturally aspirated engine. The solid lines show brake power as a function of engine speed at various equivalence ratios. The dashed lines are iso-bsfc lines. As expected, the solid lines tail off at high speeds due to increasing friction losses. Volumetric efficiency ranges from $74.8 \%$ at 4000 rpm, equivalence ratio equal to 0.75 to $89.9 \%$ at $6000 \mathrm{rpm}$, equivalence ratio equal to 0.35 . Fuel consumption decreases as engine speed decreases due to increased importance of friction and cooling losses.

Figure 2 is an engine map for an engine identical to the baseline engine but with no leakage or crevice flows. Comparing Figures 1 and 2, there is a dramatic difference in output and the shape of iso-bsfc curves. The computer program's leakage and crevice models are subject to the following constraints:

- Leakage area is constant throughout the cycle.

- Crevice volume is constant throughout the cycle.

- Leakage and crevice flows are lumped at apex seals. 
- Leakage flow is quasi-steady and 1-D.

- Crevice temperature equals rotor temperature. Note that for the cases in this study, leakage area and crevice volume were estimated based on cold engine measurements. The above constraints probably lead to leakage and crevice flows having an exaggerated influence on engine performance. In an actual engine, the apex seal is thought to be seated against the trochoid housing during most of the cycle and probably lifts off the housing for brief periods of time. Therefore, the constant leakage area assumption leads to too-large leakage effects. However, the dramatic differences between Figures 1 and 2 indicate leakage and crevice flows may degrade performance badly and should be modeled and measured.

Figure 3 compares baseline and no-leakage engine volumetric efficiencies. Leakage and crevice flows influence volumetric efficiency by raising the chamber temperature and pressure during induction.

To add perspective, predicted engine performance was compared to performance of several idealized engines. Cycle analyses were performed for an engine running at $6000 \mathrm{rpm}$ and equivalence ratios between 0.35 and 0.75 . The results are plotted in Figure 4. An explanation of the legend is provided below.

A Air-Standard Otto cycle

B Results from the computer model for the baseline engine with no leakage, no crevice flow, no friction, no heat transfer and very fast combustion.*

C Baseline engine with no leakage or crevice flows, no friction or ancillary losses and no heat transfer to the walls.

D Baseline engine with no leakage or crevice flows and no friction or ancillary losses

E Baseline engine with no leakage or crevice flows.

F Baseline engine

* To check the accuracy of the program's approximations to gas properties, a hypothetical cycle consisting of isentropic compression, constant volume combustion to equilibrium composition, isentropic expansion and constant pressure intake/exhaust was compared to curve B. Equilibrium composition and specific heat ratio after combustion were calculated at the various equivalence ratios and assumed constant during expansion. The resulting curve was nearly identical to $B$. The power was slightly lower than $B$ at low equivalence ratios and slightly higher at high equivalence ratios. The powers were equal around equivalence ratio equal to 0.5 .
Figure 5 illustrates the predicted influence of loss mechanisms on engine performance. The bottom curve shows performance inclusive of all loss submodels. The highest curve shows air-standard Otto cycle output for an equivalent engine. The curves in between were generated by removing losses one by one from the baseline engine. Because some loss mechanisms are interdependent, Figure 5 provides only qualitative information on losses.

Since leakage losses are exacerbated by high chamber pressure, the leakage and crevice flows become more pronounced at high loads. Recall that leakage area is constant during the cycle, leading to probable over-prediction of leakage effects. Friction (including seals, bearings and ancillary losses) appears an important loss mechanism for this naturally aspirated engine. Note, however, that the friction losses aren't changed much by turbocharging; friction losses would consume a smaller fraction of a turbocharged engine's indicated power. Heat transfer and combustion rate appear a lesser influence, but possibly provide a more accessible route to performance improvement. As expected, reducing heat transfer and speeding up combustion provides greater benefit at higher load. Figure 6 shows results similar to those of Figure 5 . Figure 6 is a plot of $b s f c$ for engines $A-E$.

COMBUSTION STUDY In the next study, the combustion rate was varied via the parameters $\theta$, (combustion initiation angle), $\theta_{m}$ (angle at which the maximum fuel energy release rate occurs) and $\left(\frac{d Q}{d \theta}\right)_{m}^{*}$ (the maximum fuel energy release rate normalized by the total amount of fuel energy added per cycle [units are $\mathrm{deg}^{-1}$ ]). The following equations relate these parameters:

$$
\begin{gathered}
\frac{d Q}{d \theta}=m_{f} \times L H V \times\left(\begin{array}{c}
d Q \\
d \theta
\end{array}\right)_{m}^{*}\left(\begin{array}{c}
\theta-\theta_{s} \\
\theta_{m}-\theta_{s}
\end{array}\right) \\
\theta_{s} \leq \theta \leq \theta_{m} \\
\frac{d Q}{d \theta}=m_{f} \times L H V \times\left(\begin{array}{c}
d Q \\
d \theta
\end{array}\right)_{m}^{*} e^{-\frac{A^{-\theta_{m}}}{r}} \\
\theta_{m} \leq \theta \leq \theta_{e p o}
\end{gathered}
$$

where $\theta$ is crank angle, $m_{f}$ is the mass of fuel introduced per cycle, $L H V$ is fuel lower heating value and subscript epo denotes the exhaust port opening.

Varying the combustion rate influenced not only the chamber pressure profile, but also the heat 
transfer to the walls, the exhaust gas temperature and to a small extent the seal friction (since underseal pressure is related to chamber pressure). Three types of alterations were made to the combustion rate. For four base cases, the maximum heat release rate, the angle for maximum heat release rate and the combustion initiation angle were varied. In the four cases, the minimum burn time is progressively reduced. The four base cases are described in Table 3 .

Table 3: Combustion Study Parameters

\begin{tabular}{|c|c|c|c|}
\hline Case & \multicolumn{1}{|c|}{$\theta_{s}$} & $\theta_{m}$ & $\left(\frac{d Q}{d \theta}\right)_{m}^{*}$ \\
1 & $-30^{\circ}$ & $+15^{\circ}$ & $0.025 \mathrm{deg}^{-1}$ \\
2 & $-10^{\circ}$ & $+10^{\circ}$ & $0.045 \mathrm{deg}^{-1}$ \\
3 & $-5^{\circ}$ & $+5^{\circ}$ & $0.050 \mathrm{deg}^{-1}$ \\
4 & $-1^{\circ}$ & $+1^{\circ}$ & $0.150 \mathrm{deg}^{-1}$ \\
\hline
\end{tabular}

Figure 7 shows qualitatively how the maximum heat release rate effects the heat release rate profile. Likewise, the influence of the angle for maximum heat release rate and the combustion initiation angle are shown in Figures 8 and 9, respectively.

In the first combustion study, the normalized maximum heat release rate $\left(\frac{d Q}{d \theta}\right)_{m}^{*}$ was varied for cases $1-4$ (Table 3). Engine output was plotted as functions of $\left(\frac{d Q}{d \theta}\right)_{m}^{*}$ in Figure 10 and burn time in Figure 11. Burn time is taken as the number of crank angle degrees for $90 \%$ of the fuel to burn. These figures demonstrate that the fastest burn is not always the best burn. For example, when the amount of time in the linear portion of the burn profile is long (case 1), engine output is highest when burn time is around $60^{\circ}$. As the time for the linear portion of the burn is reduced, the burn time for maximum output also reduces. Very fast combustion leads to higher chamber pressure and temperature. Therefore, there are greater cooling and leakage losses when burning rate is increased. These losses account for the shape of the curves in Figures 10 and 11 .

Angle for the maximum heat release rate, $\theta_{m}$, was varied in the next study. The results are plotted in Figures 12 and 13. In Figure 12, brake power is plotted against $\theta_{m}$ for cases 1,2 and 3 and in Figure 13 , brake power is plotted against burn time for the same cases. The influence of $\theta_{m}$ on performance is not as profound as the influence of the maximum heat release rate. Once again, the fastest burn does not necessarily lead to the highest output.
In the final combustion study, the combustion initiation angle was varied for cases 1,2 and 3 . The results are plotted in Figures 14 and 15. For Figure 14 , combustion initiation angle is the abscissa and output power is the ordinate. Figure 15 is a plot of the same results against burn time. Again, the shortest burn time is not the best.

The preceding results are valid only if the heat release rate profile resembles the profile in Figure 1. The results may be invalid, for example, for a twospark-plug rig, since that profile in Figure 1 was formulated for a one-plug rig.

INSULATION STUDY Performance was calculated for supercharged, DISC RCEs with various LHR coatings. The results were reported in reference [9]. Now, the same schemes are examined for a turbocharged engine. This study is merited, since insulating the engine changes the exhaust gas energy and influences turbocharger operation.

The following engines were studied:

(1) baseline engine with aluminum housings and iron rotor. Housing and rotor thicknesses are $11.25 \mathrm{~mm}$. Aluminum thermal conductivity, $k$, is $k=240 \mathrm{~m} \mathrm{~K}_{\mathrm{K}}^{\mathrm{W}}$ and for iron, $k=54.7 \mathrm{~m} \mathrm{~K}^{\mathrm{W}}$. Thermal conductivity is not allowed to vary with temperature.

(2) All components are $10.76 \mathrm{~mm}$ of titanium (for Titanium, $\left.k=19.4 \frac{\mathrm{W}}{\mathrm{m} \mathrm{K}}\right)$.

(3) the trochoid housing is insulated coated with two insulating layers: $0.127 \mathrm{~mm}$ of $\mathrm{Cr}_{2} \mathrm{O}_{3}(k=$ $1.21_{\mathrm{m} \mathrm{K}}^{\mathrm{W}}$ ) on top of $0.635 \mathrm{~mm}$ of post-densified Zirconia ( $\left.k=2.91 \frac{\mathrm{w}}{\mathrm{m}}\right)$. The rotor is iron and side housings are aluminum.

(4) Rotor is coated with $0.635 \mathrm{~mm}$ of post-densified Zirconia.

(5) Trochoid and side housings are insulated with $0.127 \mathrm{~mm}$ of $\mathrm{Cr}_{2} \mathrm{O}_{3}$ and $0.635 \mathrm{~mm}$ of postdensified Zirconia and rotor is insulated with $0.635 \mathrm{~mm}$ of post-densified Zirconia.

(6) All components are insulated with hypothetical material of near-zero conductivity.

(7) Hypothetical engine with no heat transfer. All engines were turbocharged and ran at $5500 \mathrm{rpm}$ and equivalence ratio equal to 0.75 . Other engine geometry and operating conditions are the same as those of the baseline engine.

Figure 16 shows how fuel energy is used. The dark grey solid portion of the bars shows the fraction of energy lost through rotor, trochoid housing and side housing cooling. The hatched portions show the fraction resulting in shaft work. The small grey sections are the energy used in overcoming friction 
and ancillary losses and the dotted section indicates how much fuel energy goes out the exhaust port. As seen in Figure 16, cooling losses in the rotary engine account for less fuel than in a crank-piston engine. There are two reasons for this. First, rotary engines are run at higher speeds than crank-piston engines. Second, the hottest portion of the cycle occurs only in one part of the structure. Consequently, there are cool parts of the trochoid housing and side housings on which very little heat transfer takes place.

Because cooling losses are relatively small, engine performance is not improved significantly unless most of the cooling losses are blocked (cases 6 and 7). For engines $1-5$, the chosen insulation schemes change cooling load only slightly and thermal efficiency even less. Even in cases 6 and 7, the thermal efficiency of the engine does not increase as much as the fraction energy going out the exhaust port. Recall that insulation does not change the combustion process in this model. Such effects might result in greater thermal efficiencies of insulated engines, though no such efficiency gains have been measured to date for rotary engines.

Insulation's impact on brake power, $b s f c$, volumetric efficiency and exhaust temperature is shown in Table 4.

Table 4: Output and $b s f c$ for Insulated Engines

\begin{tabular}{|c|c|c|c|c|}
\hline Case & $\begin{array}{c}\wp \\
(\mathrm{kW})\end{array}$ & $\begin{array}{c}b s f c \\
\left(\frac{8}{\mathrm{kWh} h}\right)\end{array}$ & $\begin{array}{c}\eta_{v} \\
(\%)\end{array}$ & $\begin{array}{c}T_{\mathrm{e}} \\
(\mathrm{K})\end{array}$ \\
\hline 1 & 65.3 & 274 & 92.1 & 887 \\
2 & 66.1 & 271 & 91.9 & 897 \\
3 & 65.8 & 272 & 92.1 & 892 \\
4 & 65.5 & 274 & 92.0 & 888 \\
5 & 67.8 & 268 & 91.9 & 900 \\
6 & 81.8 & 248 & 89.6 & 985 \\
7 & 91.3 & 241 & 93.0 & 972 \\
\hline
\end{tabular}

In Table $4, p$ is brake power, $\eta_{v}$ is volumetric effciency (based on average intake manifold pressure and temperature) and $T_{e}$ is time averaged engine exhaust temperature. Despite increased exhaust energy, power and $b s f c$ improvements are small when the proposed insulations are applied. As expected, trochoid housing insulation improves performance more than rotor insulation. Unfortunately, trochoid housing insulation presents more wear and application difficulties than rotor insulation. The upper limit for power gain from insulation is $25 \%$ over baseline power (case 6 ). The corresponding limit for $b s f c$ reduction is $9.5 \%$. Comparing cases 6 and 7 , adding insulation reduces volumetric efficiency by increasing wall temperature and gas temperature during induction. The result is lower power than in a hypothetical, no-heat-transfer engine.

To end the insulation study, cooling losses for the trochoid housing, rotor and side housings for engines $1-5$ are shown in Figure 17. The insulation schemes that reduced the cooling load the most are the all-titanium engine (case 2) and the all-insulated engine (case 5). Adding insulation to the sideplates appears unproductive, since there is so little cooling through the sideplates.

TURBOCHARGING STUDY Several turbocharger-related issues are addressed in this section of the paper. First, turbocharged engine performance is compared to the baseline, naturally aspirated engine performance. Second, the influence of engine back-pressure on performance is outlined. Back-pressure effects must be considered when assessing turbocompounding viability. Finally, results from an exhaust port timing study are presented. Changing the shape of the exhaust port was studied as an avenue toward better turbocharger-engine matching for a high-output engine.

Figure 18 is a turbocharged engine performance map. The "guts" of the engine are identical to the baseline engine. The turbocharger performance was input from maps provided by John Deere Tech., Inc. [16]. In the turbocharged engine studies, two sets of turbocharger maps were used: those for the insulation study and turbocharged engine map, and those for the high-power engine exhaust port shape study.

Comparing Figures 18 and 2, the turbocharged engine provides far more power at a much lower fuel consumption rate. The lowest $b s f c$ for the turbocharged engine occurs at high load and speed; the naturally aspirated engine has worse fuel consumption at high load and speed. Naturally aspirated engine performance is limited by air trapping and friction, turbocharged engine performance is limited by engine/turbocharger match, maximum allowable chamber pressure and compressor and turbine characteristics. Note that the simulation was not run at high speeds for equivalence ratios above 0.55 . This is because the compressor and turbine corrected speeds became very high and their efficiencies dropped rapidly at the high loads and speeds. Consequently, the computer program could not predict engine performance accurately at these conditions.

Turbocompounding may provide an avenue for rotary engine power boost and $b s f c$ reduction. However, if the compounding turbine increases engine 
back pressure too much, reduced shaft power and air flow rate may negate the added turbine's positive effects. To explore the viability of turbocompounding a rotary engine, the simulation was run at 6500 rpm and $8000 \mathrm{rpm}$ and $\phi=0.65$ with various intake and exhaust manifold pressures. First, the intake manifold pressure was set to 1.904 atm (27.9 psi) and the exhaust manifold pressure was varied from $1 \mathrm{~atm}$ (14.7 psi) to $2.1 \mathrm{~atm}$ ( $30.9 \mathrm{psi})$. Next, the intake manifold pressure was set to 1.6 atm (23.5 psi) and the exhaust manifold pressure was varied from 1 atm (14.7 psi) to 1.7 atm (25.0 psi). Finally, the intake manifold pressure was set to $1.3 \mathrm{~atm}(19.1$ psi) and the exhaust manifold pressure varied from $0.8 \mathrm{~atm}$ (11.8 psi) to $1.4 \mathrm{~atm}$ (20.6 psi).

Figure 19 shows the resulting power as a function of exhaust manifold pressure. The curves in Figure 19 all have the same shape. In an effort to generalize the results of Figure 19, the output power for each curve was normalized by the power when exhaust and intake manifold pressures are equal. The normalized power was plotted against normalized exhaust manifold pressure (normalized by intake manifold pressure). Figure 20 shows these results. Although it is hard to follow distinct curves in Figure 20, it is clear that for all the curves, raising the back pressure does not reduce the output power too much until $\frac{P_{c m}}{\Gamma_{i m}}$ is around 0.9 .

In addition to maintaining engine shaft power when raising back pressure, air flow rate should also be maintained. Otherwise, turbocharger turbine work decreases, compressor work decreases, intake manifold decreases and shaft power decreases. Normalized air flow rate, $\dot{m}_{\text {air }}^{*}$, is plotted against normalized exhaust pressure in Figure 21 (air flow rate is normalized by air flow rate when exhaust pressure and intake pressure are equal). The data points fall neatly onto two curves. In part, this is because, in the simulation, port discharge coefficients do not vary during the cycle and, for these runs, intake and exhaust manifold pressure are held steady during the cycle. Figure 21 indicates $\frac{P_{a m}}{P_{i m}}$ should be kept below around 0.8 to maintain air flow rate.

When the turbocharged engine (Figure 18) runs at $6500 \mathrm{rpm}$ and $\phi=0.65, \frac{P_{e m}}{\Gamma_{i m}}=0.80$. At 8000 rpm and $\phi=0.55$, the ratio is 0.74 . Although no rematching of the turbomachinery was performed for these cases, adding a compounding turbine does not appear practical with the given turbocharger. Power and air flow losses would become severe if back pressure were increased.

In this paper's final study, the influence of ex- haust port timing on engine performance was calculated. This work was performed because recent measurements indicate increased exhaust flow may improve engine operation at very high power levels [17].

Both exhaust port area and exhaust port timings (crank angles for the port opening and closing) influence shaft power and turbocharger map. To open the port too early results in lost P-V work. To leave the port open too long may result in poor turbocharger/engine matching. In another study [17], it was shown that for an engine similar to that studied in this paper, increasing the exhaust port area without changing timing could substantially decrease bsfc. Of course, increasing the exhaust port area may not be possible without changing the timings.

In the current study, the angle at which the exhaust port opens, $\theta_{\text {r.po, }}$, and the angle at which it closes, $\theta_{e p c}$, were varied. Port area was set equal to $12.09 \mathrm{~cm}^{2}$. $\theta_{\text {epc }}$ varied from $595^{\circ}$ to $655^{\circ *}$ and $\theta_{\text {cpo }}$ varied from $185^{\circ}$ to $225^{\circ}$. A different turbocharger was used in this study because higher power levels were desired. The engine geometry was the same as the baseline engine. Engine speed was $8250 \mathrm{rpm}$.

In Figure 22, brake power is plotted against fuel flow rate for $595^{\circ}<\theta_{\text {r.p. }}<655^{\circ}$. For these cases, $\theta_{\text {cpo }}=208.7^{\circ}$. The earlier the port closes, the better. The influence on brake power is small until $\theta_{c p r} \approx 625^{\circ}$. Figure 23 shows bs $f c$ for the same exhaust port timings. Exhaust port timing can have a large influence on $b s f c$.

Figures 24 and 25 show brake power and $b s f c$ when $\theta_{e p c}=610.5^{\circ}$ and $185^{\circ}<\theta_{e p o}<225^{\circ}$. For these cases, $\theta_{c p c}=610.5^{\circ}$. The best power and $b s f c$ occur when $\theta_{\text {epo }}=205^{\circ}$. When $\theta_{\text {epo }}<205^{\circ}$, $\mathrm{P}-\mathrm{V}$ work is lost because the exhaust "stroke" is shortened. This is especially troublesome at high loads. When $\theta>205^{\circ}$, the exhaust port is open too long and the turbocharger-engine match is not optimal.

An attempt was made to generalize the results of Figures $22-25$. Figure 26 is a plot of Brake Power v. exhaust port length. Exhaust port area and width were left the same for all cases. The dashed lines give brake power for a given fuel flow rate when $\theta_{\text {epo }}$ is varied. The solid lines correspond

* Angles are given in crank angle degrees after top center. Top center is the minimum volume rotor position near the spark plug and fuel injectors. $1080^{\circ}$ make up one cycle. 
to varying $\theta_{\text {epc }}$. Similarities in the dashed and solid lines are due in part to the similar effect the exhaust port length has on turbocharger-engine match. To run this engine at high power levels, it may be necessary to keep the port length at about $3 \mathrm{~cm}$ (1.2 in) or less for the given port area. Figure 27 is a plot of $b s f c$ v. exhaust port length.

\section{SUMMARY AND DISCUSSION}

Following is a short description of how the computer program operated during the simulations and a summary of some of the major points.

The computer program used in this study takes about $1 \mathrm{~min}, 30 \mathrm{~s}$ of CPU time on a VAX 8600 mainframe computer to calculate engine performance for a naturally aspirated engine at one operating point. For a turbocharged engine, the CPU time varies from $2 \mathrm{~min}$ to $5 \mathrm{~min}$. Sometimes, no solution is possible because turbocharger and engine are incompatible. Convergence is based on cycle initial and final properties. The cycle is converged when chamber pressure, chamber temperature, manifold pressures and temperatures and wall temperatures at the beginning and end of the cycle are within some convergence criteria of each other. In this paper, for naturally aspirated engines, the convergence criterion was $0.5 \%$. For medium-power turbocharged engines, the criterion was $0.25 \%$. For high-power turbocharged engines the criterion was $0.1 \%$.

Following is a summary of the paper's main points.

- At medium load, the baseline naturally aspirated engine is only about $50 \%$ as efficient as an equivalence air-standard Otto cycle. Friction and ancillary losses play a large role in reducing the baseline engine's efficiency.

- Depending on the shape of the combustion heat release rate profile, the best combustion may not be the fastest one.

- Even for a turbocharged engine, proposed insulation schemes did not increase efficiency or power very much. No analysis was made of the impact on cooling load (pump sizes, cooling system weight, etc.).

- If adding a compounding turbine to a turbocharged engine raises the back pressure above $80 \%$ of the average intake manifold pressure, the net power gain from the compounding turbine may be small. This is because (1) volumetric efficiency and brake power fall as exhaust pressure approaches intake pressure and (2) air flow rate falls drastically as exhaust pressure approaches intake pressure.
- When predicting performance of a rotary engine with an enlarged port, changes in exhaust port timing should be included. In general, ports that open late and close early provide better performance than ports of the same area that open early and close late.

\section{REFERENCES}

[1] Norbye, J.P., The Wankel Engine, p. 108, Chilton Book Co., Philadelphia, PA, 1972.

[2] Mount, R.E., and LeBouff, G.A., "Advanced Stratified Charge Rotary Engine Design," SAE paper 890324, SAE, Warrendale, PA, 1989.

[3] "Automotive Engineering," Vol. 99, No. 11, pp. 68-69, SAE, Warrendale, PA, Nov., 1991.

[4] Abraham, J., and Bracco, F.V., "Fuel-Air Mixing and Distribution in a Direct-Injection Stratified-Charge Rotary Engine," SAE paper 890329, SAE, Warrendale, PA, 1989.

[5] Abraham, J., and Bracco, F.V., "3-D Computations to Improve Combustion in a StratifiedCharge Rotary - Part II: a Better Spray Pattern for the Pilot Injector," SAE paper 892057, SAE, Warrendale, PA, 1989.

[6] Raju, M.S., "Heat-Release and Performance Characteristics of a Dual Ignitor Wankel Engine," SAE paper 920303, SAE, Warrendale, PA, 1992.

[7] Badgley, P.R., Doup, D., and Kamo, R., "Analysis and Test of Insulated Components for Rotary Engine," SAE paper 890326, SAE, Warrendale, PA, 1989.

[8] Irion, E.C., and Mount, R.E., "Stratified Charge Rotary Engine Critical Technology Enablement Program - Phase III," NASA CR189106, in press, 1992.

[9] Bartrand, T.A., and Willis, E.A., "Performance of a Supercharged Direct-Injection Stratified-Charge Rotary Combustion Engine," NASA TM 103105, NASA Lewis Research Center, Cleveland, $\mathrm{OH}, 1990$.

[10] Norman, T.J., "A Performance Model of a Spark Ignition Wankel Engine," Master's thesis, Massachusetts Institute of Technology, June, 1983.

[11] Roberts, J.A., Norman, T.A., Ekchian, J.A., and Heywood, J.B., "Computer Models for Evaluating Premixed and DISC Wankel Engine Performance," SAE paper 860613, SAE, Warrendale, PA, 1986.

[12] Nguyen, H.L., Addy, H.E., Bond, T.H., and Chun, K.S., "Performance and Efficiency Evaluation and Heat Release of a Direct-Injection 
Stratified-Charge Rotary Engine," SAE paper 870445, SAE, Warrendale, PA, 1987.

[13] Gatowski, J.A., Balles, E.N., Chun, K.M., Nelson, F.E., Ekchian, J.A., and Heywood, J.B., "Heat Release Analysis of Engine Pressure Data," SAE paper 841359, SAE, Warrendale, PA, 1984.

[14] Woschni, G., "A Universally Applicable Equation for the Instantaneous Heat Transfer Coefficient in the Internal Combustion Engine," SAE paper 670931, SAE, Warrendale, PA, 1967.

[15] Stanten, R.A., "Heat Transfer and Performance Calculations in a Rotary Engine," Master's thesis, Massachusetts Institute of Technology, August, 1987.

[16] Dimplefeld, P., personal correspondence, ca. 1989.

[17] Willis, E.A., and McFadden, J.J., "NASA's Rotary Engine Technology Enablement Program - 1984 through 1991," SAE paper 920311, SAE, Warrendale, PA, 1992. 


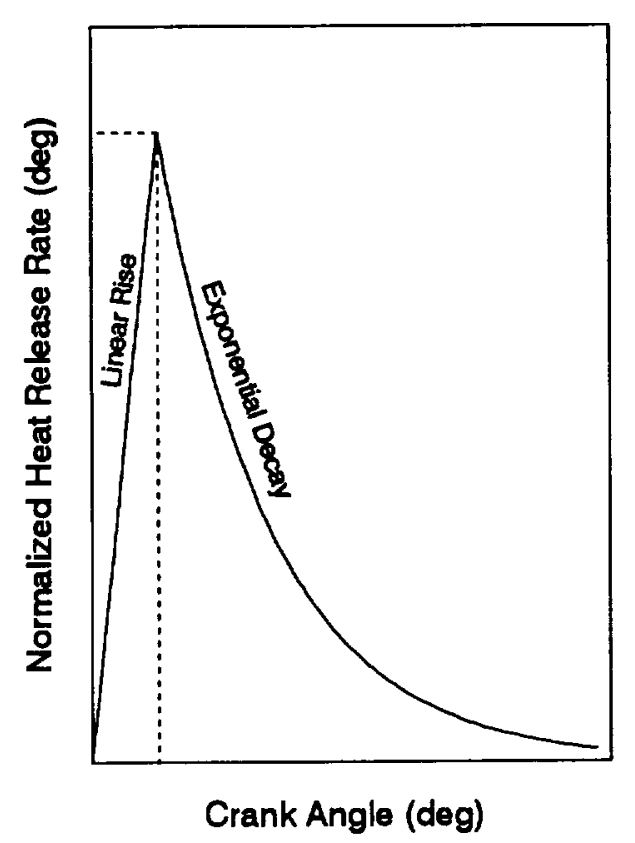

Figure 1: Heat Release Rate Profile

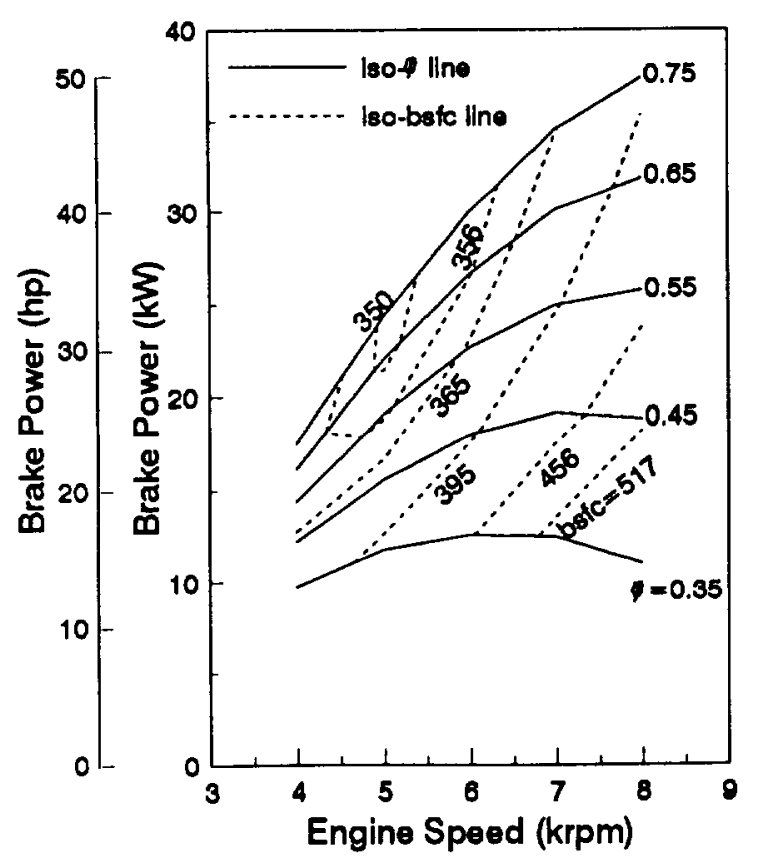

Figure 2: Baseline Engine Map

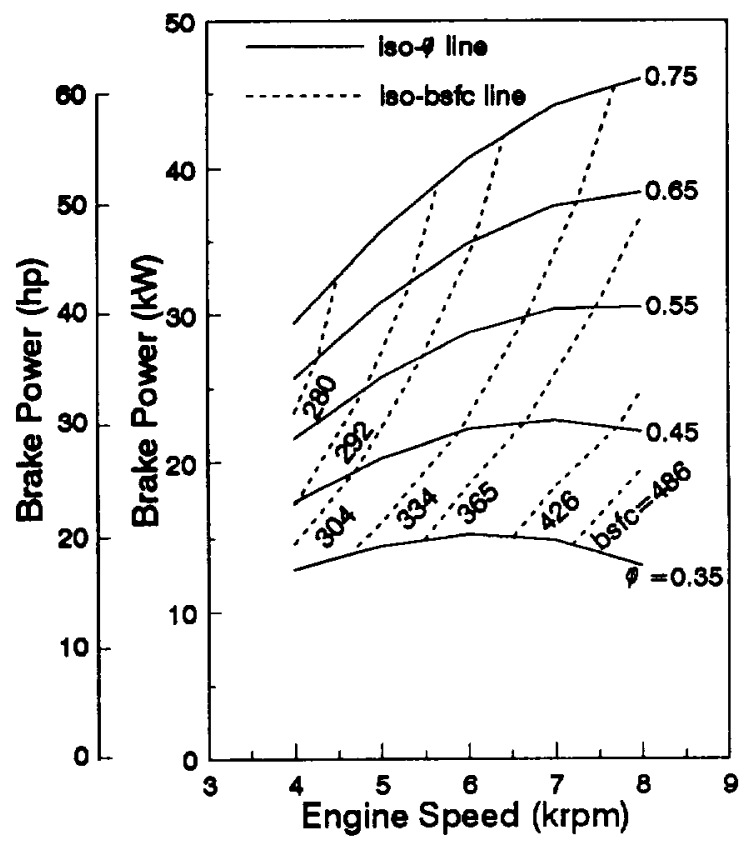

Figure 3: No Leakage, No Crevice Engine Map

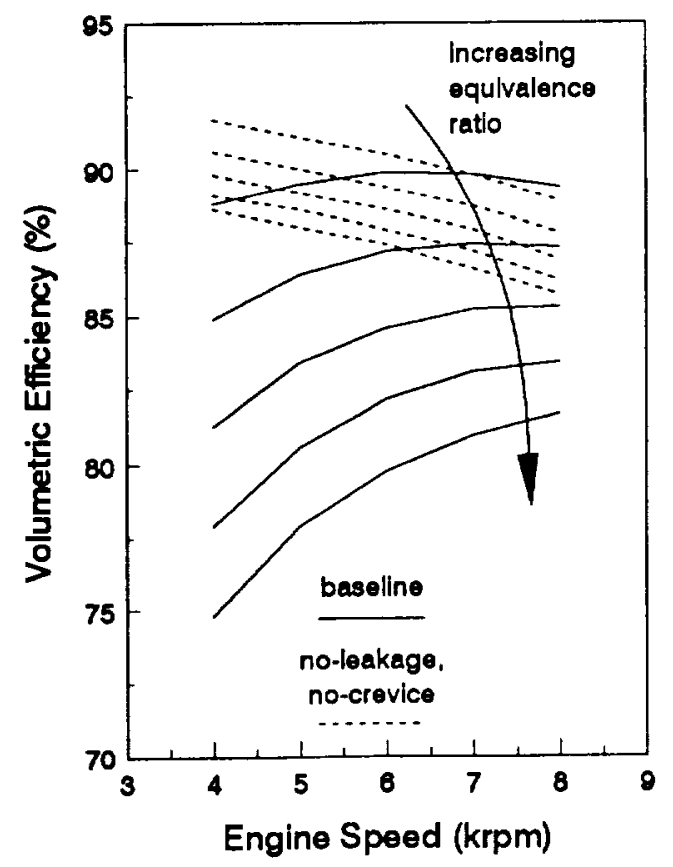

Figure 4: Influence of Leakage on Volumetric Efficiency 


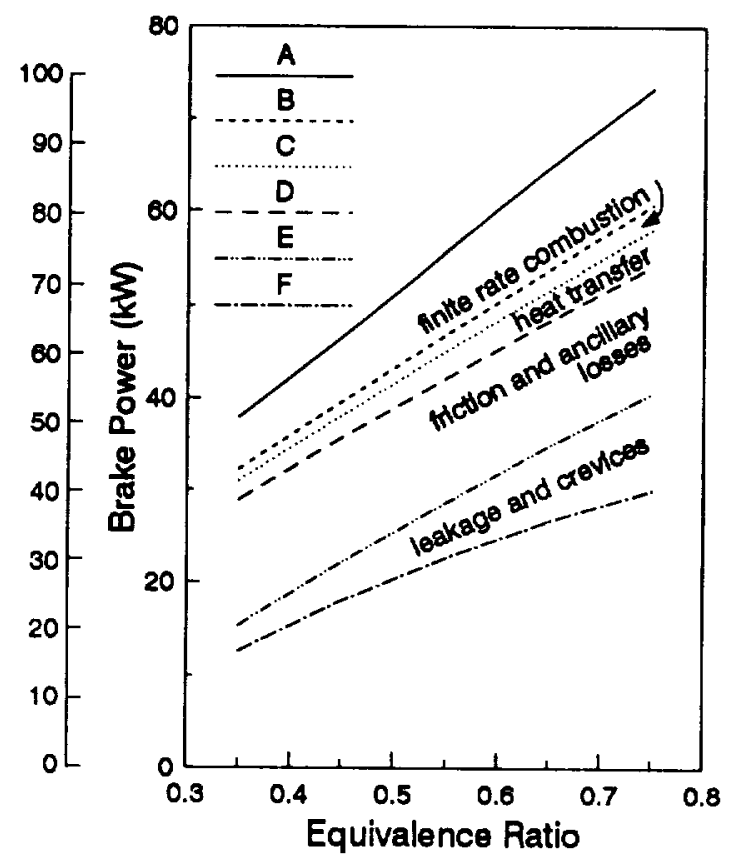

Figure 5: Idealized Cycle Outputs

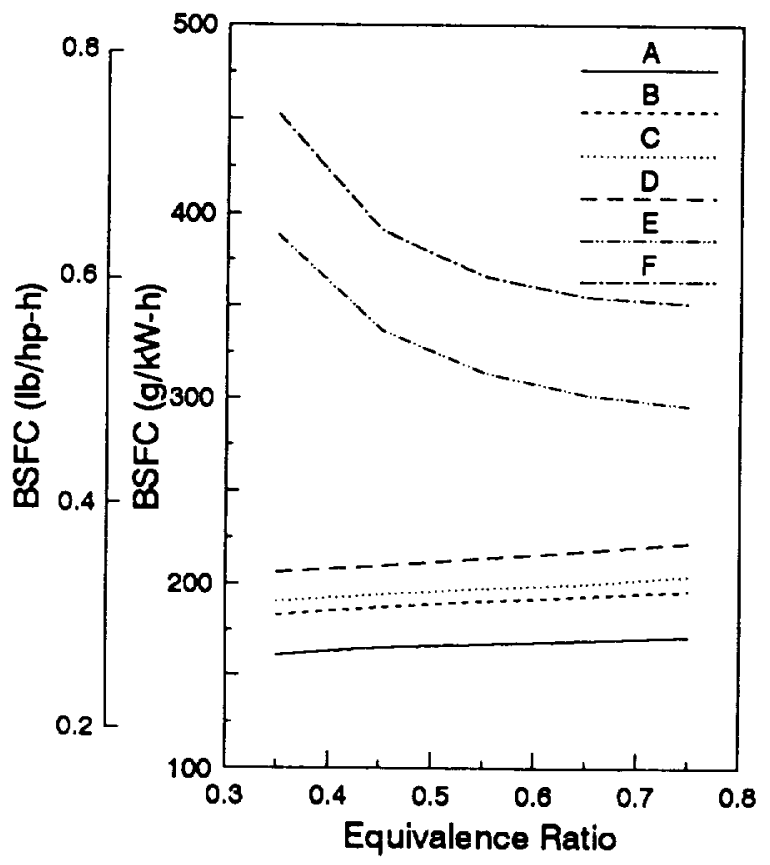

Figure 6: Idealized Cycle Fuel Consumptions

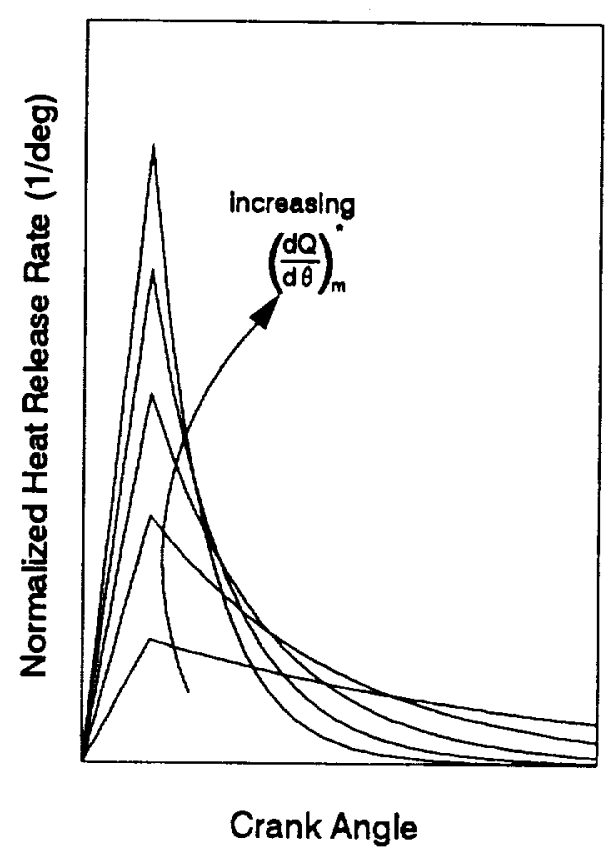

Figure 7: Heat Release Rate Profiles for Various Maximum Heat Release Rates

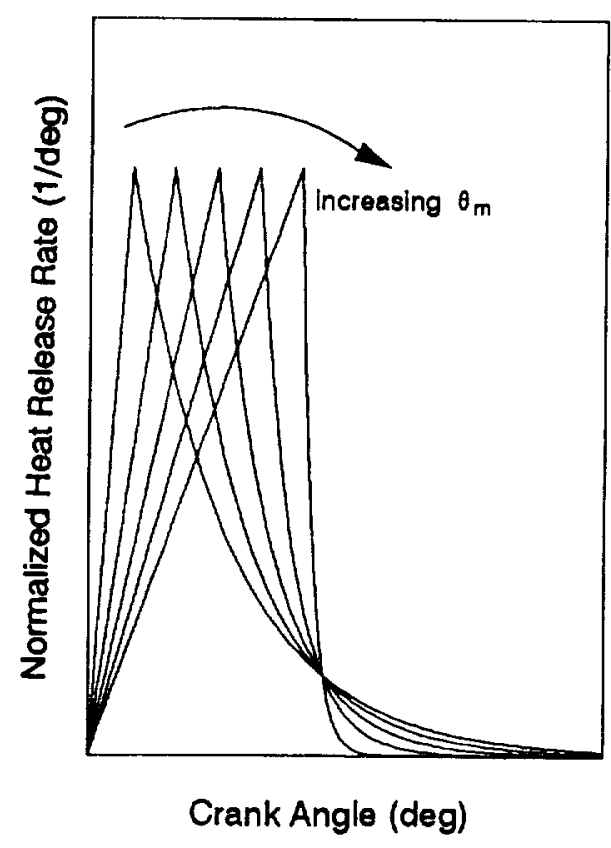

Figure 8: Heat Release Rate Profiles for Various Angles for Maximum Heat Release Rate 


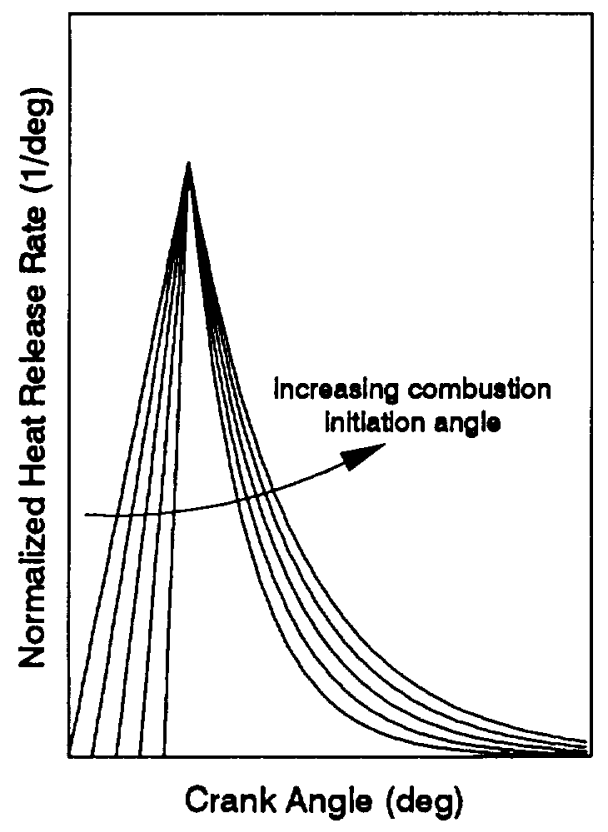

Figure 9: Heat Release Rate Profiles for Various Combustion Initiation Angles

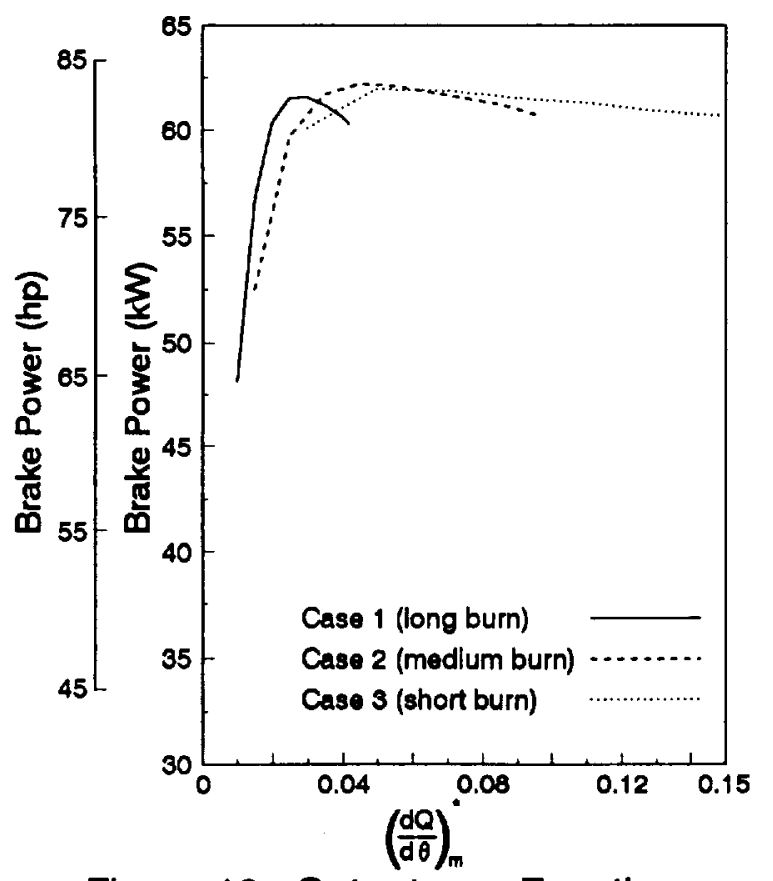

Figure 10: Output as a Function of Maximum Heat Release Rate

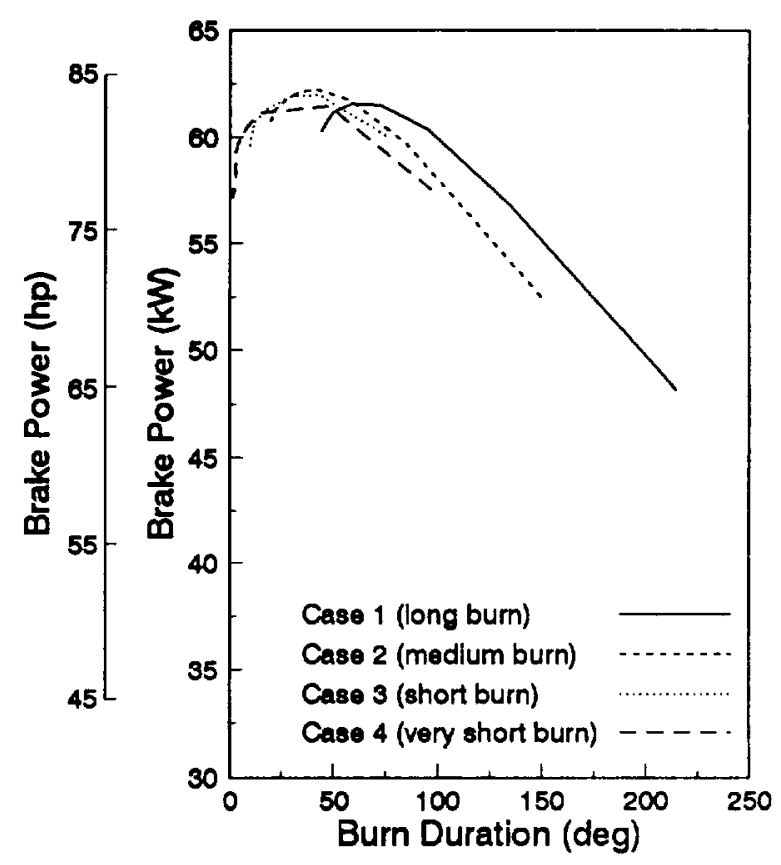

Figure 11: Output v. Burn Time as Maximum Heat Release Rate Varies

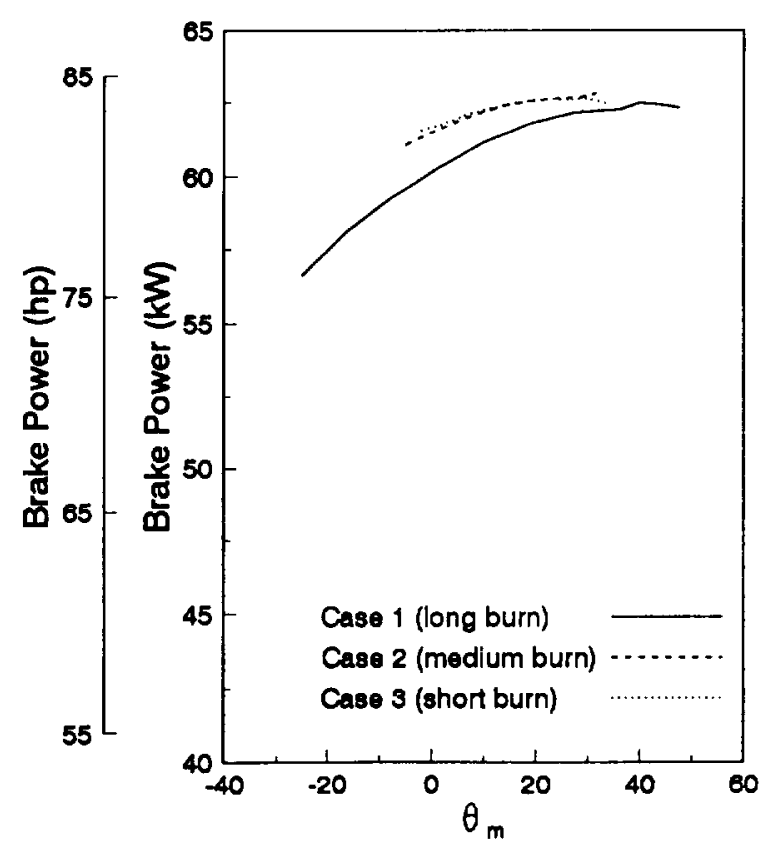

Figure 12: Output as a Function of Angle for Maximum Heat Release Rate 


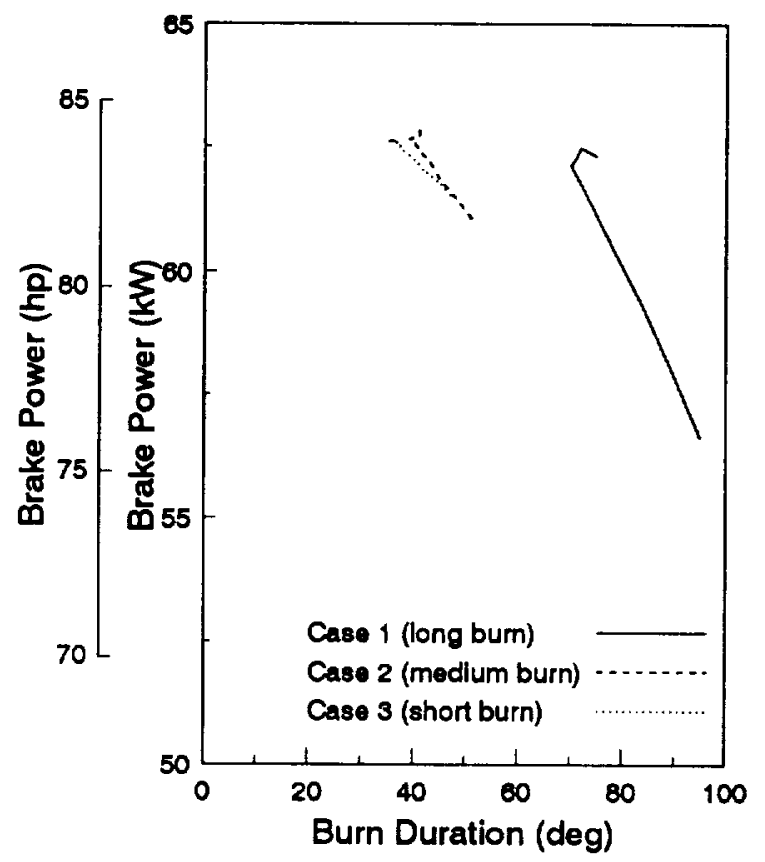

Figure 13: Output v. Burn Time as Angle for Maximum Heat Release Rate Varies

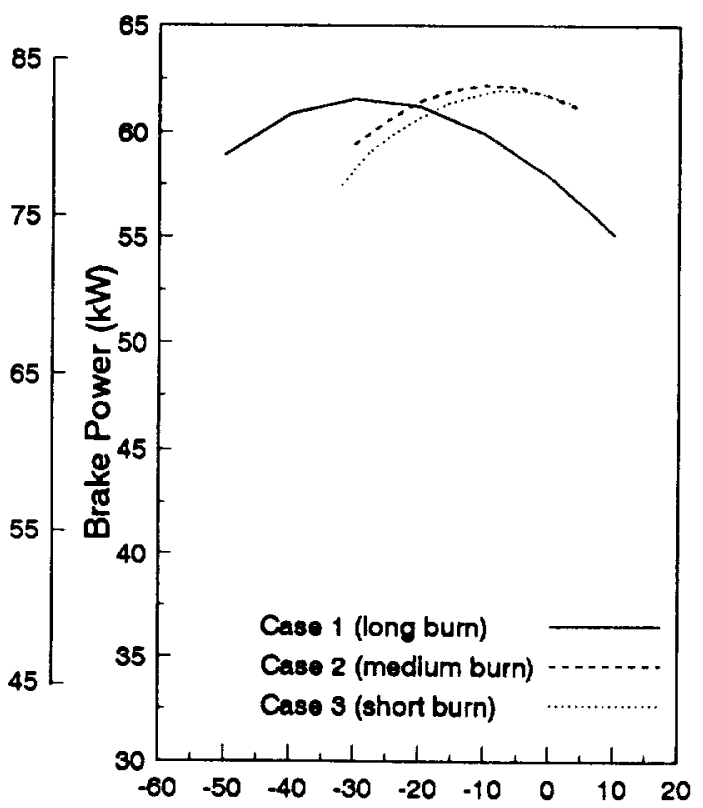

Combustion Initiation Angle (deg)

Figure 14: Output as a Function of Combustion Initiation Angle

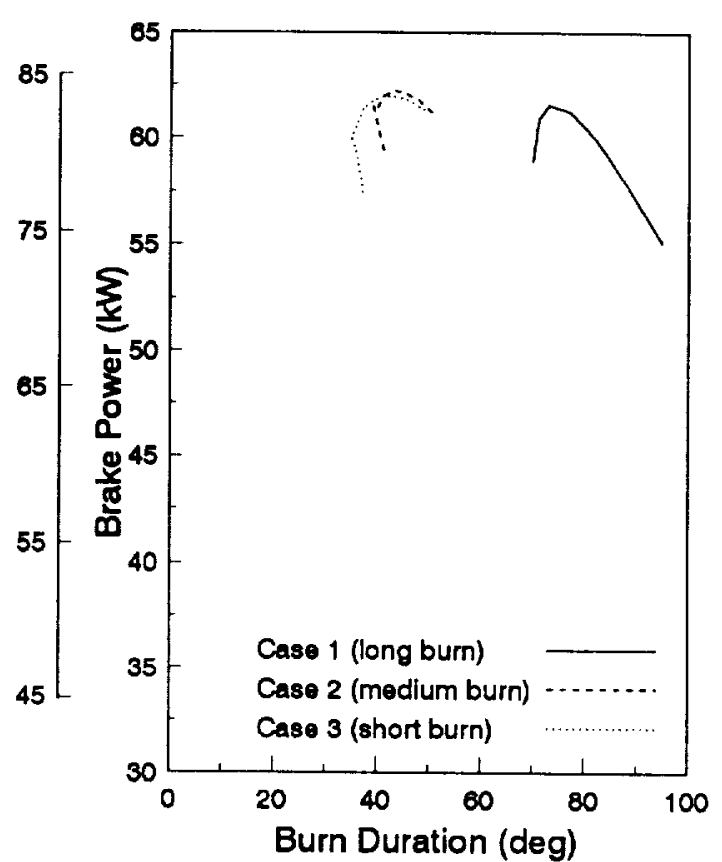

Figure 15: Output v. Burn Time as Combustion Initiation Angle Varies

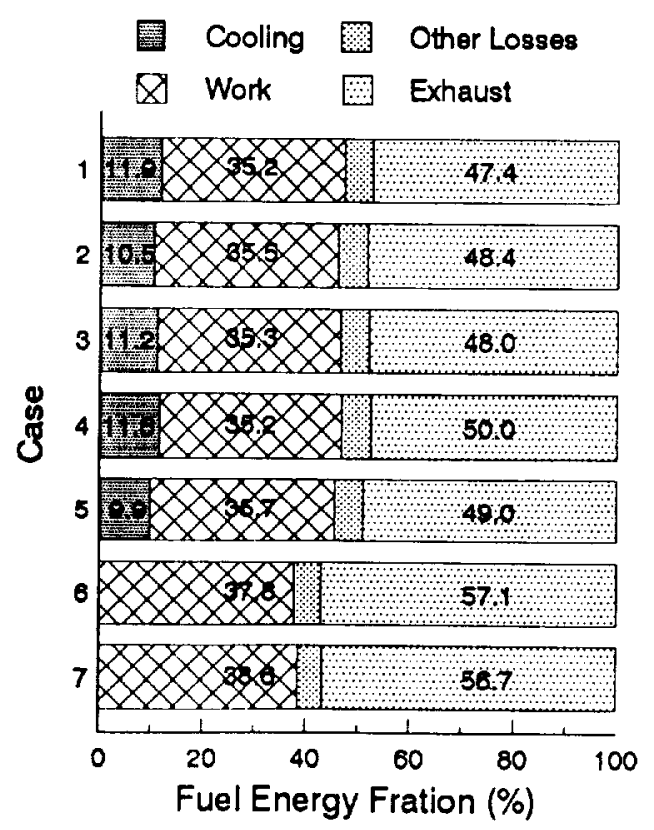

Figure 16: Fuel Energy Breakdown $5500 \mathrm{rpm}$, Equivalence ratio $=0.75$ 


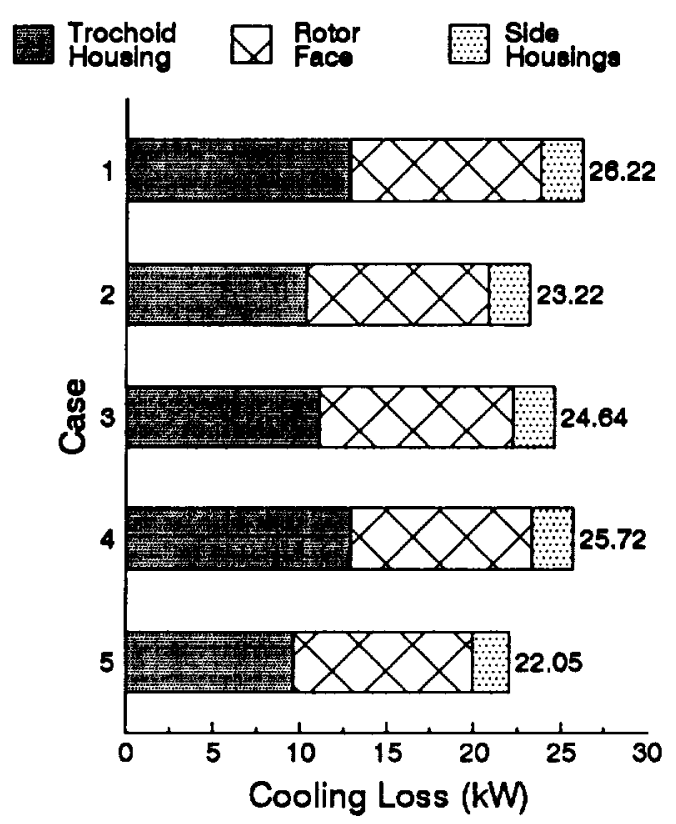

Figure 17: Component Cooling Losses

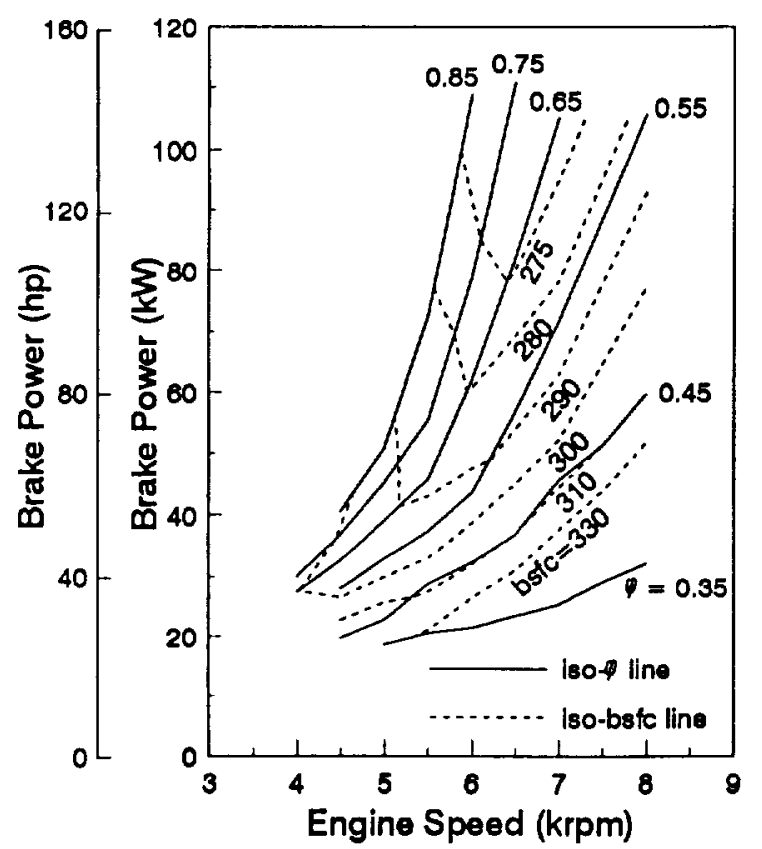

Figure 18: Turbocharged Engine Map

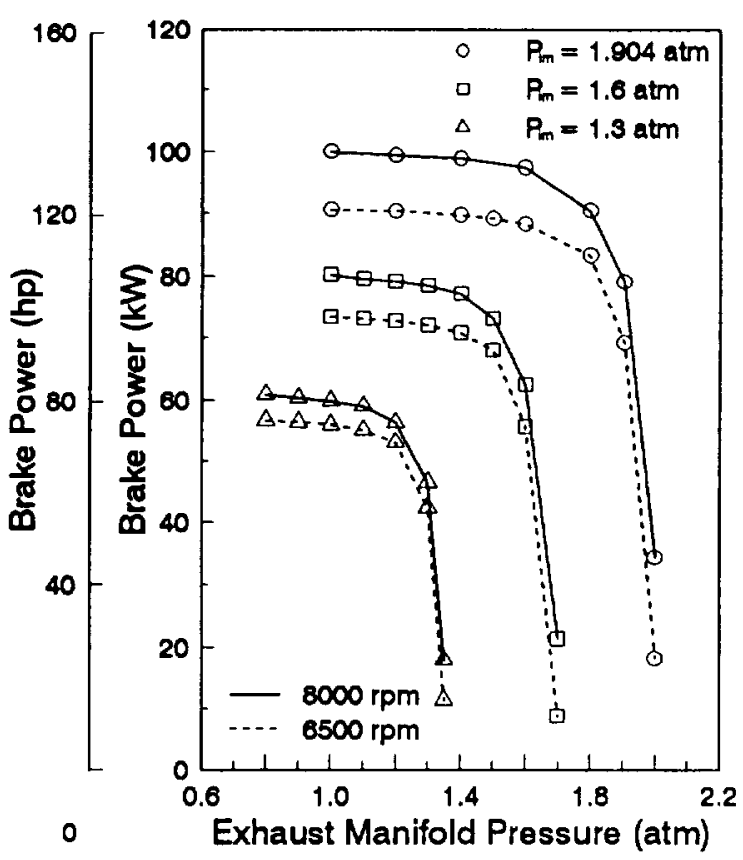

Figure 19: Influence of Exhaust Manifold Pressure on Power

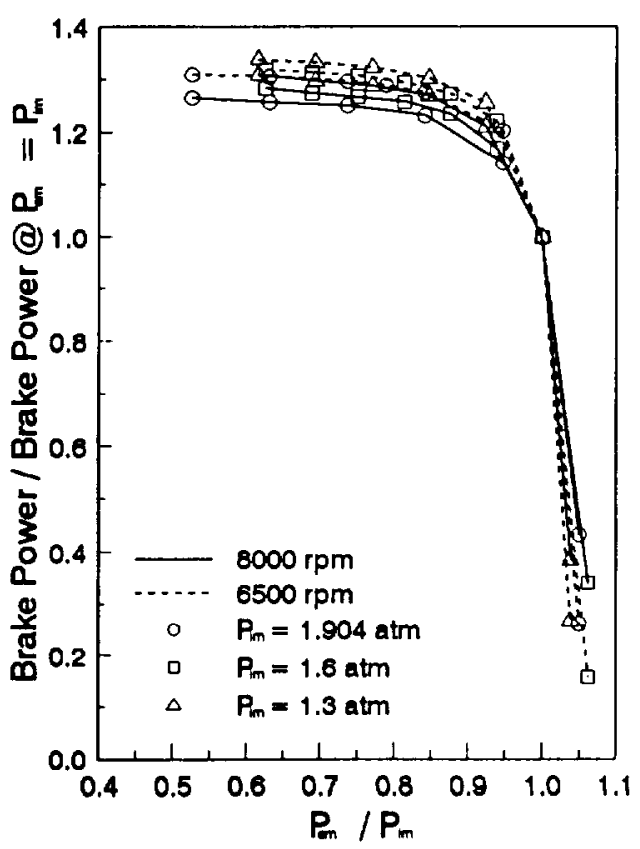

Figure 20: Normalized Power v. Normalized Exhaust Pressure 


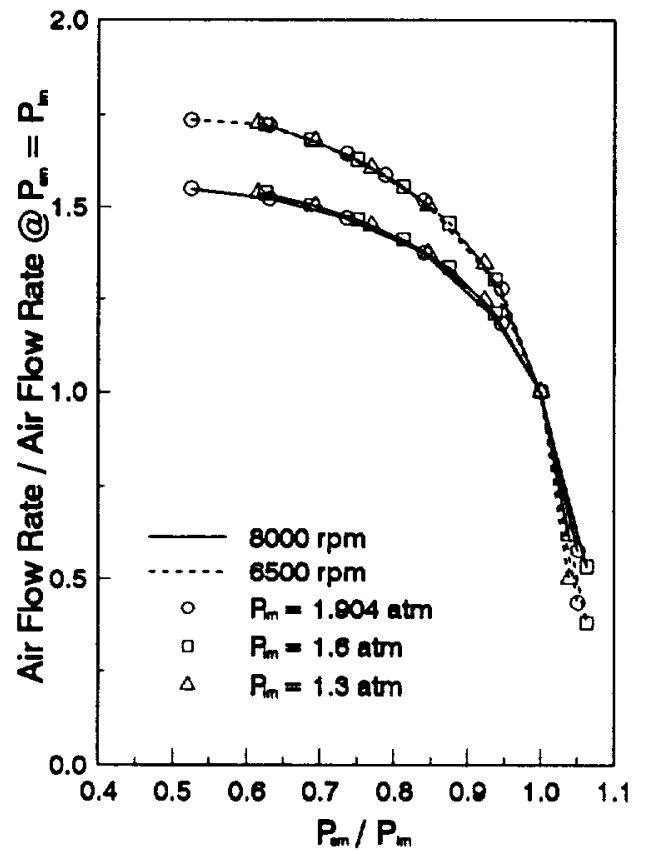

Figure 21: Normalized Air Flow v. Normalized Exhaust Pressure

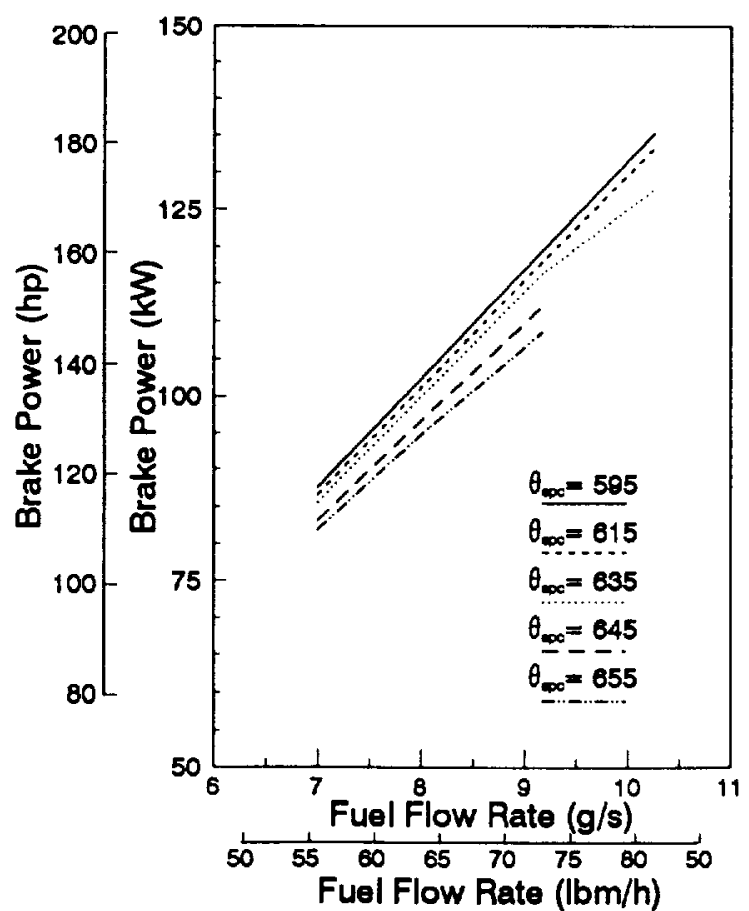

Figure 22: Exhaust Port Closing Angle Effect on Brake Power

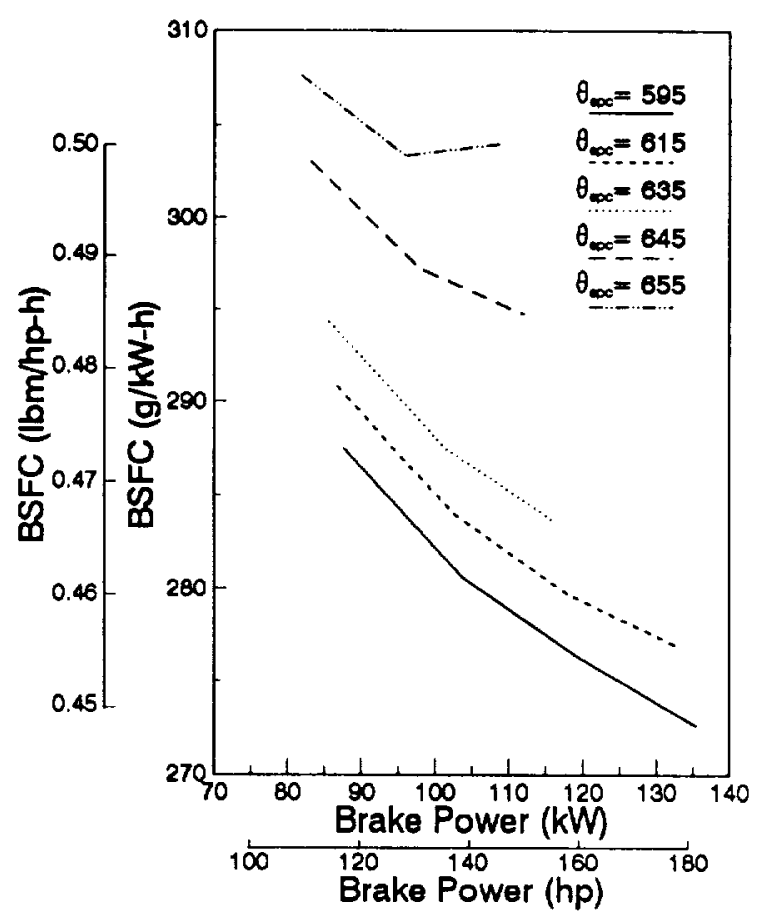

Figure 23: Exhaust Port Closing Angle Effect on Fuel Consumption

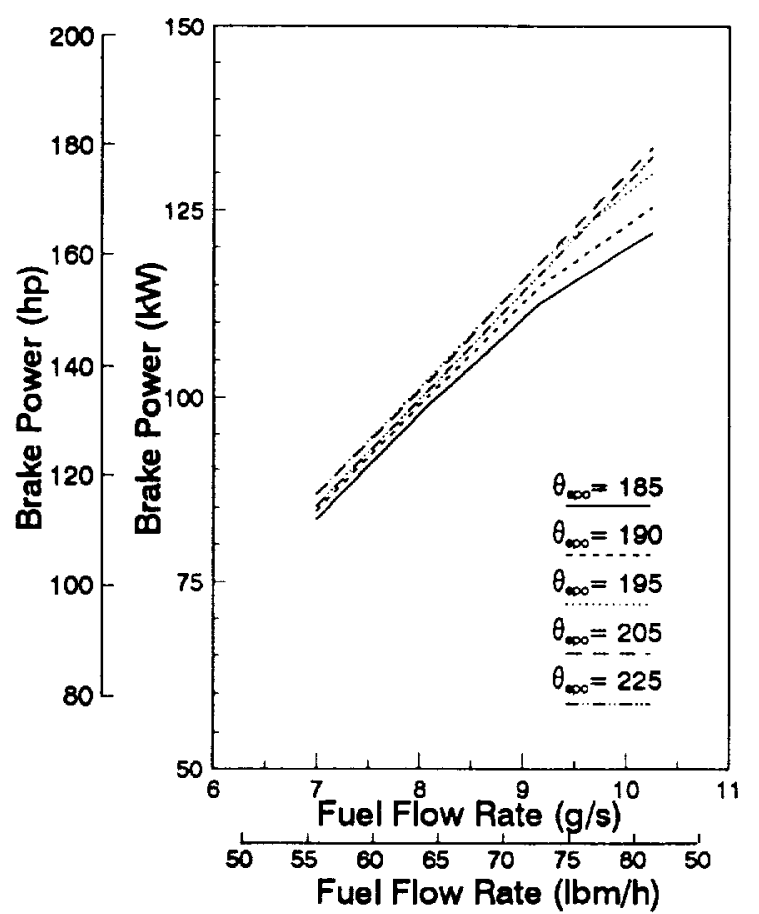

Figure 24: Exhaust Port Opening Angle Effect on Brake Power 


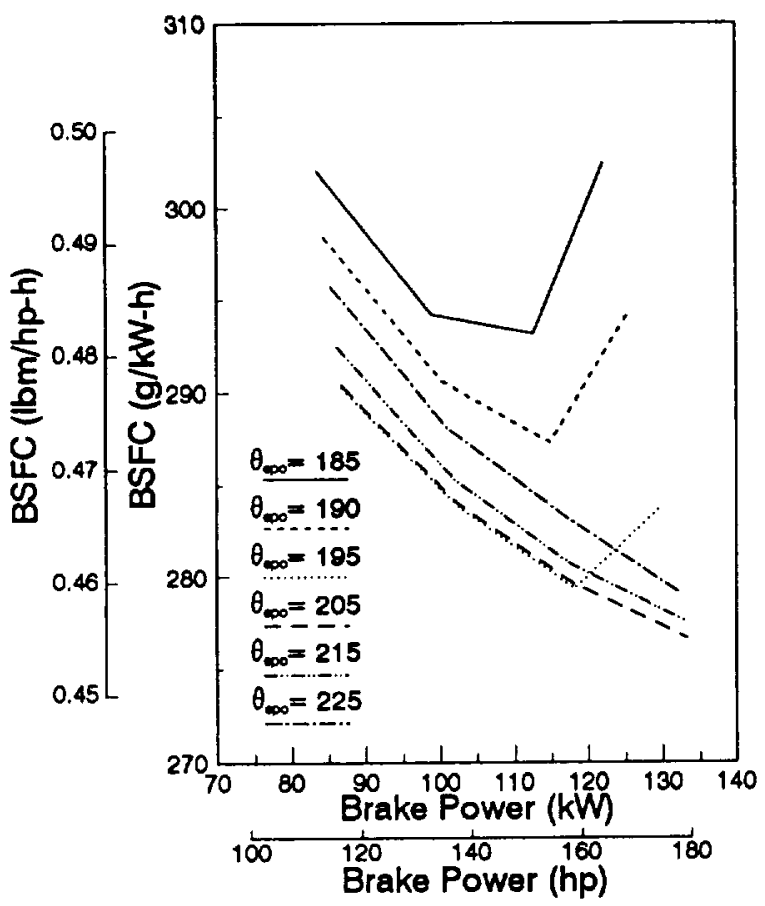

Figure 25: Exhaust Port Opening Angle Effect on Fuel Consumption

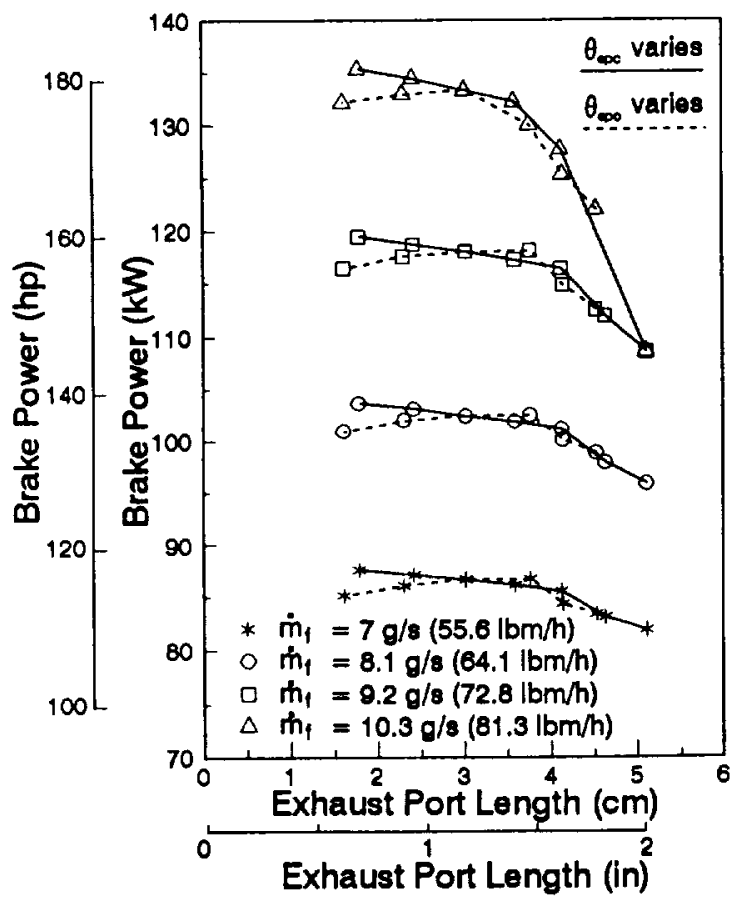

Figure 26: Exhaust Port Length v. Brake Power

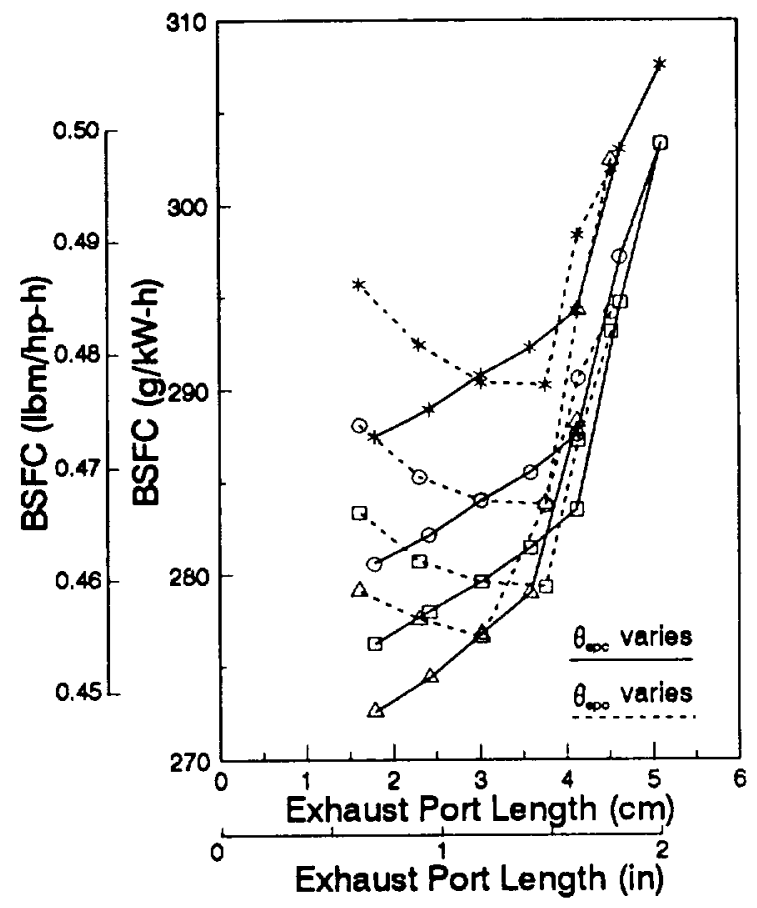

Figure 27: Exhaust Port Length v. BSFC 
Public reporting burden for this collection of information is estimated to average 1 hour per response, including the time for reviewing instructions, searching existing data sources, collection of information, including suggestions for reducing and reviewing the collection of information. Send comments regarding this burden estimate or any other aspeci at this Davis Highway, Suite 1204. Arlington, VA 22202.4302 and

Davis Highway, Suite 1204. Arlington, VA 22202.4302, and to the Office of Management and Budget. Paperwork Reductton Pioject (0704-0188), Washinglon, DC 20503

\begin{tabular}{|l|l|l}
\hline 1. AGENCY USE ONLY (Leave blank) & $\begin{array}{c}\text { 2. REPORT DATE } \\
\text { March } 1992\end{array}$ & $\begin{array}{c}\text { 3. REPORT TYPE AND DATES COVERED } \\
\text { Final Contractor Report }\end{array}$ \\
\hline
\end{tabular}

4. TITLE AND SUBTITLE

Rotary Engine Performance Limits Predicted

by a Zero-Dimensional Model

\section{AUTHOR(S)}

Timothy A. Bartrand and Edward A. Willis

\section{PERFORMING ORGANIZATION NAME(S) AND ADDRESS(ES)}

Sverdrup Technology, Inc.

Lewis Research Center Group

2001 Acrospace Parkway

Brook Park, Ohio 44142

9. SPONSORING/MONITORING AGENCY NAMES(S) AND ADDRESS(ES)

National Acronautics and Space Administration

Lewis Rescarch Center

Cleveland, Ohio 44135-3191

\section{FUNDING NUMBERS}

WU-505-62-12

8. PERFORMING ORGANIZATION REPORT NUMBER

$E-6880$

10. SPONSORING/MONITORING AGENCY REPORT NUMBER

NASA CR-189129

\section{SUPPLEMENTARY NOTES}

Project Manager, Rohert C. Evans, Propulsion Systems Division, NASA Lewis Research Center, (216) 433-3400. Prepared for the International Congress and Exposition sponsored by the Society of Automotive Enginecrs, Detroit, Michigan, February $2428,1992$.

12a. DISTRIBUTION/AVAILABILITY STATEMENT

Unclassified - Unlimitco

Subject Category 107

\section{ABSTRACT (Maximum 200 words)}

A parametric study was performed to determine the performance limits of a rotary combustion engine. This study shows how well increasing the combustion rate, insulating and turbocharging increase brake power and decrease fuel consumption. Several generalizations can be made from the findings. First, it was shown that the fastest combustion rate is not necessarily the best combustion rate. Second, several engine insulation schemes were employed for a turbocharged engine. Performance improved only for a highly insulated engine. Finally, the viability of turbocompounding and the influence of exhaust port shape were calculated. Rotary engine performance was predicted by an improved zero-dimensional computer model based on a model developed at the Massichusets Institute of Technology in the $1980 \mathrm{~s}$. Independent variables in the study included combustion heat release rate, manifold pressures, wall thermal properties, leakage area and exhaust porl geometry. Additions to the computer program since its results were last published include turbocharging, manifold modeling and improved friction power loss calculation. The baseline engine for this study is a single rotor 650 ce direct-injection stratified-charge engine with aluminum housings and a stainless steel rotor. Engine maps are provided for the haseline and turbocharged versions of the engine.

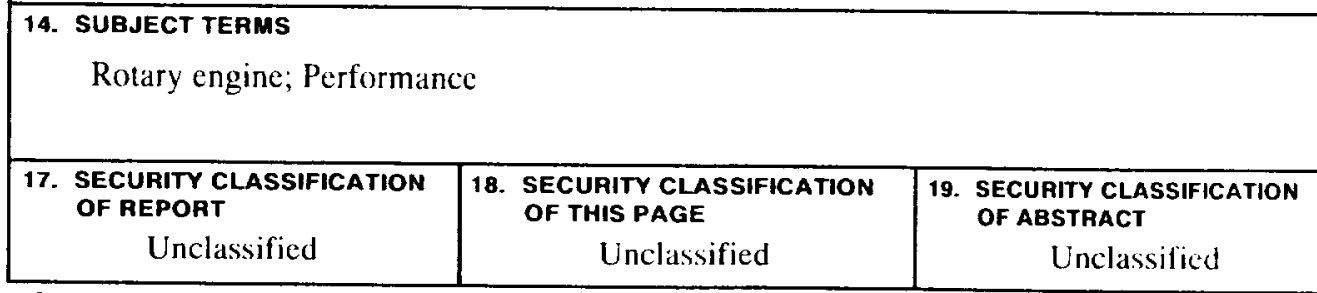

NSN 7540-01-280-5500

\begin{tabular}{|} 
15. NUMBER OF PAGES \\
18 \\
\hline 16. PRICE CODE \\
AOH3
\end{tabular}

20. LIMITATION OF ABSTRACT 